\title{
INDOOR AIR QUALITY IN U.K. SCHOOL CLASSROOMS VENTILATED BY NATURAL VENTILATION WINDCATCHERS
}

\author{
Benjamin M. Jones ${ }^{\mathrm{a} *}$ and Ray Kirby ${ }^{\mathrm{b}}$ \\ a The Bartlett School of Graduate Studies, University College London, Central House, 14 Upper Woburn Place, \\ London, WC1H ONN. \\ ${ }^{\mathrm{b}}$ School of Engineering and Design, Mechanical Engineering, Brunel University, Uxbridge, Middlesex, UB8 3PH. \\ * Corresponding author. b.jones@ucl.ac.uk; Tel.: +44(0)2031089013.
}




\section{ABSTRACT}

The provision of good IAQ in schools is important both for the health of students and in maximising educational achievement. It is, however, common for school classrooms to be significantly under-ventilated and this can lead to high levels of $\mathrm{CO}_{2}$ and other pollutants. Natural ventilation offers the potential to improve IAQ within schools whilst at the same time reducing running and maintenance costs. Accordingly, this article examines a natural ventilation strategy based on the use of a roof mounted split-duct Windcatcher ventilator. Here, 16 U.K. classrooms are studied and $\mathrm{CO}_{2}$, temperature, relative humidity and ventilation rates are measured for the summer and winter seasons. Results show that during the summer months the ventilator is capable of significantly improving ventilation rates as well as reducing $\mathrm{CO}_{2}$ levels, especially when used in combination with open windows; however, in the winter months, the ventilator is seen not to open for a sufficient length of time and so $\mathrm{CO}_{2}$ levels rise above those required in the standards. Thus, the ventilator is shown to have the potential to improve IAQ within school classrooms, but the operation of the ventilator should be carefully controlled in order to realise these benefits.

\section{PRACTICAL IMPLICATIONS}

It is common for ventilation rates in school classrooms to fall below the levels required by relevant standards. The data presented here demonstrates that by using a top-down natural ventilation Windcatcher as part of a well designed natural ventilation strategy, ventilation rates in school classrooms can be significantly improved. 


\section{INTRODUCTION}

The adverse effect of poor indoor air quality (IAQ) on the health and productivity of building occupants is well known, see for example Mendell and Heath (2005). Poor IAQ can be particularly detrimental to children in schools who spend approximately $30 \%$ of their time inside school buildings, which is more than in any other building type other than their homes (Bakó-Biró et al. 2011). Here they are shown to be subject to a variety of pollutants from furnishings (Seppänen et al. 1999), IT equipment (Bakó-Biró et al. 2004), bio-effluents, and external pollutants such as nitrogen dioxide (Stranger et al. 2008) and carbon monoxide (Chaloulakou and Mavroidis 2002). Mendell and Heath (2005) note that there is the potential for children to sustain long lasting damage because their tissue and organs are still growing, they breath more air relative to their body mass than adults, and ventilation rates in school classrooms are often below those recommended by the various standards organisations (see Daisey et al. 2003, for example). Because ventilation is also used to control temperature and humidity, low ventilation rates also have a detrimental effect upon the comfort and health of occupants, which in schools is likely in the future to be further be compounded by the effects of climate change. Furthermore, poor ventilation rates can also lead to high $\mathrm{CO}_{2}$ levels, which have been shown to have an effect on the health and performance of occupants (Myhrvold 1996, Seppänen et al. 1999, Coley et al. 2007, Bakó-Biró et al. 2011). Conversely, Wargocki et al. (2002) show that the perceived quality of indoor air by occupants, and therefore their comfort, increases with the per capita ventilation rate, and that outdoor supply rates should exceed 25 litres per second per person ( $1 / \mathrm{s}$ - person) to reduce the risk of SBS symptoms and short-term sick leave, and to increase productivity. Furthermore, by using intervention tests in school classrooms, Wargocki and Wyon (2007a, 2007b) show that as per capita ventilation rates increase, the speed and accuracy of students performance also increases. 
Clearly, it is desirable to achieve minimum ventilation rates and here most standards specify outdoor ventilation rates to a room, and also use the internal $\mathrm{CO}_{2}$ concentration as an indicator of the ventilation rate, despite known misunderstandings of a consistent relationship between the two parameters (Persily 1997). The American Society of Heating, Refrigeration and AirConditioning Engineers Standard 62.1 (ASHRAE 2007) recommends a default minimum ventilation rate for acceptable indoor air quality in school classrooms of 6.7 to $7.4 \mathrm{l} / \mathrm{s}-$ person, depending upon the age of the children, but is generally cited in the literature as a blanket rate of $8 \mathrm{l} / \mathrm{s}$ - person (see Daisey et al. 2003). It also shows that the maintenance of a steady state $\mathrm{CO}_{2}$ concentration of $700 \mathrm{ppm}$ above ambient levels will ensure the provision of $7.5 \mathrm{l} / \mathrm{s}-$ person, and will constrain body odour. In Europe, several standards present guidelines for good indoor air quality in classrooms, see EN13779 (2004) and EN15251 (2007). EN15251 classifies IAQ into four bands of performance that correspond to the proportion of occupants that are dissatisfied with the indoor air quality $(10 \%, 20 \%, 30 \%$, and $>30 \%$ respectively) and ventilation rates of $10,7,4$, and $<4$ 1/s - person, respectively. EN13779 also classifies IAQ into high, medium, moderate, and low quality that correspond to values of $250 \mathrm{ppm}, 500 \mathrm{ppm}$, $800 \mathrm{ppm}$, and $1200 \mathrm{ppm}$ respectively for the indoor $\mathrm{CO}_{2}$ concentration above the ambient, and a per capita rate of ventilation for non-smoking rooms of $20,12.5,8$, and $51 / \mathrm{s}$ - person respectively. Various national guidelines specify other ventilation rates for classrooms; for example, Conceição and Lúcio (2006) report that the Portuguese standards is 8.31 1/s - person, Geelen et al. (2008) show that The Netherlands Standard 1089 stipulates 5.51/s - person and a guideline peak value of $\mathrm{CO}_{2}$ at $1200 \mathrm{ppm}$, and Smedje and Norback (2000) record that Swedish standards require $8 \mathrm{l} / \mathrm{s}$ - person and an internal $\mathrm{CO}_{2}$ concentration below $1000 \mathrm{ppm}$. In the U.K., Building Bulletin 101 (BB101), DfES (2006), uses $\mathrm{CO}_{2}$ as an IAQ indicator for schools and goes on to prescribe a maximum concentration of $5000 \mathrm{ppm}$ and a mean occupied concentration of $1500 \mathrm{ppm}$. Of course, in the absence of a combustion source, the rate at which $\mathrm{CO}_{2}$ is produced within a space depends on the number of occupants, as well as their size, activity, and metabolic rate (Persily 1997). Thus, one can link desired $\mathrm{CO}_{2}$ levels to 
ventilation rates and here $\mathrm{BB} 101$ specifies a minimum of $3 \mathrm{l} / \mathrm{s}-$ person, a daily mean of $5 \mathrm{l} / \mathrm{s}$ - person, and the ability to achieve a purge ventilation rate of $81 / \mathrm{s}$ - person at any given time. When compared against ASHRAE Standard 62.1 (2007) the ventilation rates prescribed by BB101 are lower, but are similar to rates specified in The Netherlands, and may be seen as a compromise between the need to dilute pollutants, to save energy, and to save money. BB101 also specifies the internal temperature for classrooms during the summer season: no more than 120 hours above $28^{\circ} \mathrm{C}$, a maximum of $32^{\circ} \mathrm{C}$, and on average the internal temperature should be no more than $5^{\circ} \mathrm{C}$ above the external temperature. It is noticeable that for schools BB101 sets no specific limits on relative humidity $(\mathrm{RH})$, although it does refer to the U.K. building regulations (ODPM 2006), which state that the RH must not exceed $70 \%$ for more than two hours in any 12 hour period, or $90 \%$ for more than one hour in any 12 hour period during the heating season.

Most of the IAQ data available for school classrooms is for mechanically ventilated (MV) classrooms, see for example Godwin and Batterman (2007) who report adequate ventilation rates in only $27 \%$ of classrooms, and Grimsrud et al. (2006) who report adequate ventilation in only 3 of 8 schools. Prill et al. (2002) measured $\mathrm{CO}_{2}$ in 3801 U.S. classrooms and found internal concentrations of over $1000 \mathrm{ppm}$ in $43 \%$ of the classrooms; later Shendell et al. (2004a) show that in 50\% of these classrooms ventilation rates are less than the ASHRAE standard rate of 7.5 1/s per person. For 50 U.S. classrooms, Shaughnessy et al. (2006) measured a mean ventilation rate of $3.91 / \mathrm{s}$ - person, which is equivalent to half of the ASHRAE Standard 62.1 requirement. Clearly, these findings for U.S. schools suggest that mechanical systems do not always provide ventilation adequate to meet national standards and this is also reflected in other parts of the world, although in Europe far fewer classrooms are MV and natural ventilation strategies that involve manually opening windows are common. For example, in Germany, windows are generally used to regulate the indoor air quality, although Hellwig et al. (2009), still report $\mathrm{CO}_{2}$ concentrations greater than $1500 \mathrm{ppm}$ 
in 7 of the 15 classrooms monitored in the Summer, and in 32 of the 36 measured in the winter. In Swedish classrooms, Smedje et al. (1997) found ventilation rates ranging from 0.1 to $22.4 \mathrm{l} / \mathrm{s}$ - person in 38 schools (27\% naturally ventilated) with an IAQ perceived to be worse in schools with a mechanical extract and best in schools with a mechanical supply and extract. In a further study on a mixture of naturally ventilated (NV) and MV classrooms, Smedje and Norback (2000) report that $77 \%$ of the schools measured failed to meet Swedish ventilation standards. In Norway, Myhrvold et al. (1996) measured 35 MV classrooms and found that only $49 \%$ of classrooms would meet ASHRAE Standard 62.1 and $74 \%$ would meet the U.K. BB101 Standard. In the Netherlands, Van Dijken et al. (2006) show $\mathrm{CO}_{2}$ concentrations to be in excess of $1000 \mathrm{ppm}$ for a median average of $80 \%$ of the time for seven schools between April and May, and for $77 \%$ of the time for eleven schools measured between February and March. Geelen et al. (2008) also report median $\mathrm{CO}_{2}$ concentration exceeded 1000pm during teaching hours in 81 classes taken in $20 \mathrm{NV}$ primary schools. For 62 NV classrooms in Athens, Greece, Santamouris et al. (2008) measured 29\% of classrooms with a mean $\mathrm{CO}_{2}$ concentration above 1500 ppm during teaching hours, and approximately $77 \%, 55 \%$, and $38 \%$ of classroom have a mean ventilation rate during teaching hours of less than 8,5 , and $3 \mathrm{l} / \mathrm{s}$ - person respectively. Santamouris et al. (2008) also collate measurements of ventilation rate and internal $\mathrm{CO}_{2}$ concentration found in the literature for 1187 classrooms during occupied hours (with $287 \mathrm{NV}$ and $900 \mathrm{MV}$ ), it is shown that $25 \%$ and $53 \%$ of $\mathrm{NV}$ classrooms have a mean $\mathrm{CO}_{2}$ concentration of less than $1000 \mathrm{ppm}$ and $1500 \mathrm{ppm}$, respectively, and for MV classrooms, 55\% and $85 \%$ have a mean $\mathrm{CO}_{2}$ concentration of less than $1000 \mathrm{ppm}$ and $1500 \mathrm{ppm}$, respectively. Furthermore, the database also shows that 50\%, 30\%, and 5\% of $\mathrm{NV}$ classrooms have a mean ventilation rate during teaching hours greater than 3,5 and $81 / \mathrm{s}-$ person respectively, while $99 \%, 61 \%$, and $50 \%$ of $\mathrm{MV}$ classrooms have a ventilation rate greater than 3, 5 and 81/s - person respectively. In the U.K. Coley and Beisteiner (2002) measured seven $\mathrm{NV}$ classrooms reported a mean internal $\mathrm{CO}_{2}$ concentration of $1957 \mathrm{ppm}$ for occupied hours in winter. In a related study Beisteiner and Coley (2002) measured four NV 
classrooms in the summer and report that only two of the classrooms achieved a mean $\mathrm{CO}_{2}$ concentration of below 1500 p.p.m, largely because the mean ventilation rates for each classroom are less than 3.6 1/s - person. More recently, Mumovic et al. (2009) monitored 18 classrooms during winter time and show that all six classrooms that exceeded the required mean $\mathrm{CO}_{2}$ levels used a natural ventilation strategy (based on opening windows). Clearly, Mumovic et al. identify problems with a natural ventilation strategy based solely on opening windows and that such a strategy is unlikely to suffice for modern school designs.

The data reported here for school classrooms indicate that, when judged against local ventilation standards, school classrooms are significantly under-ventilated. Furthermore, if geographical, architectural, and seasonal considerations are ignored, the ventilation rate in a $\mathrm{NV}$ classroom is, on average, much lower than in a MV classroom, and that only about half of the NV classrooms would meet the U.K. BB101 Standard for $\mathrm{CO}_{2}$, whilst only $30 \%$ would meet the ventilation rate requirements. Clearly, target ventilation rates may be achieved using appropriate mechanical ventilation, although some of the examples quoted here demonstrate that this is not always successful. However, the U.K. Government proposes that to minimise environmental impact and to reduce running and maintenance costs, school designs should "aim for natural ventilation where possible" (DfES 2002). Accordingly, in order to deliver the IAQ levels required by the relevant standards a natural ventilation strategy must meet the challenges presented by modern classrooms, such as the move towards air tight buildings and classrooms of deeper plan containing significant ICT equipment. The ventilation rates reported in the previous paragraph indicate that an NV strategy based on opening windows is on its own unlikely to deliver rates demanded by standards such as BB101. One possible alternative is to use top-down wind driven natural ventilation either on its own, or in combination with open windows. Top-down ventilation is normally achieved using a roof mounted device that channels fresh air into a room through the action of wind pressure, whilst simultaneously drawing air out of a room by virtue of the low pressure region created 
downstream of the device. This action can be observed in the wind tunnel tests of Elmualim and Awbi (2002) and Elmualim (2006) and the performance of these devices in an office was measured by Kirk and Kolokotroni (2004), who also note a significant increase in ventilation rates when operating in combination with open windows. Furthermore, by entraining air into a room from roof level, the incoming air will contain less pollutants; for example, Laxen and Noordally (1987) show that the concentration of $\mathrm{NO}_{2}$ declines with height, reverting to background levels at approximately $20 \mathrm{~m}$ above ground level; see also Gage et al. (2001). Clearly, these devices offer the potential to enhance natural ventilation rates in schools and a commercial development of this device, called a Windcatcher ${ }^{1}$, has to date been installed in over 1100 U.K. schools. These devices are currently sized on the basis of ventilation rates measured in a wind tunnel, although Jones and Kirby $(2009,2010)$ recently introduced simple semi-empirical algorithms for estimating this ventilation rate. However, there is very little data in the literature that examines how well these devices perform in situ. For example, Kirk and Kolokotroni (2004) and Kolokotroni et al. (2002b) do examine the behaviour of top-down split-duct ventilators but this is only for offices. To the best of the authors' knowledge, no equivalent studies on similar ventilators have been published for schools. Accordingly, this article reports on the performance of split-duct ventilators in 16 school classrooms and compares IAQ data against the relevant standards for the summer and winter seasons. In addition to the measurement of $\mathrm{CO}_{2}$, temperature and $\mathrm{RH}$, ventilation rates will also be measured in order to investigate the action of split-duct ventilators in a school environment. The methods used to obtain this data are described in Section 2, the results from these measurements are recorded in Section 3, and a review of the in situ performance of split-duct ventilators in schools is undertaken in Section 4.

\footnotetext{
${ }^{1}$ WINDCATCHER $^{\circledR}$ is a proprietary product of Monodraught Ltd.
} 


\section{METHODOLOGY}

Five schools and 16 classrooms ventilated by a single top-down split-duct ventilation element are examined here. At roof level each element is free from obvious shielding caused by external obstacles or architectural features and each element is chosen to be square, as this is known to maximise performance (Jones and Kirby 2009). In addition, none of the classrooms contain supplementary mechanical supply or extract ventilation. A split-duct ventilator works by channelling air into a room under the action of wind pressure, and simultaneously drawing air out of the room by virtue of a low pressure region created downstream from the element, see Jones and Kirby (2009). The ventilation element's cross-section is divided diagonally into quadrants running the length of the element. Depending on the angle of the wind, each quadrant either channels air into or out of the room. At its base, a series of flow control dampers are used to regulate the ventilation rate with their position governed by the temperature in the room. The relevant parameters of the split-duct ventilators used in this study are given in Table 1. Here, each school is assigned an alphabetical prefix and each classroom monitored within a school is given a numerical suffix. All of the school buildings were built after 2003 and are located in urban areas in the south of England. The cross sectional area (CSA) of each ventilator takes into account the presence of an acoustic lining, which is normally made from foam and covers the duct walls and the diagonal dividers. It is interesting to note here that the mean volume of the classrooms is $254 \mathrm{~m}^{2}$, which is approximately one third larger than those measured by Mumovic et al. (2009) (170m²), and Beisteiner and Coley (2002) $\left(182 \mathrm{~m}^{2}\right)$.

All of the classrooms examined here are have a single wall of double glazing, which in classrooms F2 and F4 is augmented by clerestory windows (here $77 \%$ of total glazing area). At school F all of the windows are sealed, but at the other schools some of the windows can be opened manually and the estimated opening areas for these windows is presented in Table 
1. One hundred measurements of ventilation rates have been obtained under controlled conditions, where possible, with windows both open and shut. All measurements were undertaken in empty classrooms during normal occupied hours and throughout the year to test a range of different environmental conditions. However, the $\mathrm{CO}_{2}$ measurements must be undertaken during normal occupied hours and so we cannot say if the windows were open or shut during each monitored period. Note also that the windows of classroom G3 are not shielded; the classrooms of school $\mathrm{E}$ are shielded by a balcony, and those of schools $\mathrm{C}$ and $\mathrm{F}$ have solar fins and slats, respectively, to reduce solar heat gains.

The ventilator is automatically controlled and opens according to room temperature. Dampers at the base of the ventilator duct control the flow of air into and out of the supplied room, and when a prescribed temperature or set point is reached the dampers open $20 \%$ for every $1{ }^{\circ} \mathrm{C}$ above the set point: in the winter the set point is $22^{\circ} \mathrm{C}$ and in the summer it is $16^{\circ} \mathrm{C}$. In the summer the dampers also open fully from midnight until 6am to provide night-cooling unless the internal temperature is at or below $15^{\circ} \mathrm{C}$. Occupants may override the control settings at any time by using a wall-mounted override switch that will fully open or close the dampers. The summer and winter set points are designed to modify the performance of a ventilator according to the heating season, and so monitoring was conducted during both the summer and winter seasons to determine the effectiveness of this ventilation strategy. The high winter set point suggests that the ventilator dampers should remain closed for most of this season and so it is important to determine if this is true, and then to determine the overall air quality and ventilation rate in each classroom given that the ventilator is a significant part of the ventilation strategy and its inactivity could have a detrimental effect on the air quality in a classroom during the winter months. Here, winter monitoring was conducted during weeks 44 to 4 in 2008/9, and in the summer during weeks 19-25 in 2008 and week 27 in 2007. 
Internal temperature, $\mathrm{CO}_{2}$, and $\mathrm{RH}$ measurements were taken every minute for at least five working days during each season, and for each of nine classrooms; measurements of temperature only were taken in five other classrooms using the same time interval. External temperature was measured at 5 minute intervals for all classrooms. Q-Trak 8551 sensors were used to take measurements of temperature, $\mathrm{RH}$, and $\mathrm{CO}_{2}$. Here, the temperature measurements are accurate to $\pm 0.6^{\circ} \mathrm{C}, \mathrm{CO}_{2}$ measurements are accurate to $\pm 3 \%$ and $\pm 50 \mathrm{ppm}$ at $25^{\circ} \mathrm{C}$, with an uncertainty of $\pm 0.36 \%$ per ${ }^{\circ} \mathrm{C}$ change in temperature, and $\mathrm{RH}$ readings are accurate to $\pm 3 \%$, with a $\pm 1 \%$ hysteresis. Internal temperature was also measured using Onset U10 Hobo dataloggers that are accurate to $\pm 0.4^{\circ} \mathrm{C}$ at $25^{\circ} \mathrm{C}$. External temperature was measured using DS1921 iButton Dataloggers that are accurate to $\pm 1^{\circ} \mathrm{C}$. BB101 guidelines recommend measurements are taken at seated head height, but in order to secure the equipment it was often necessary to place the equipment just above floor level, whereas on other occasions the equipment was placed at standing head height. It is noted that similar problems were encountered by Coley and Beisteiner (2002), Beisteiner and Coley (2002), and Kolokotroni et al. (2002). However, in all cases effort was taken to place the equipment away from heat sources and in regions of free air flow in order to obtain reliable and accurate readings. Ventilation rates were measured using the standard single-zone tracer gas decay method, see for example Liddament (1996). Sulphur hexafluoride $\left(\mathrm{SF}_{6}\right)$ was used as the tracer gas and was only applied to the classroom, and not any adjacent rooms or corridors. Note that the single zone gas decay method used here does not measure the rate of air flow though the ventilator, rather it measures the ventilation rate for the room and may also include airflow between the room and corridors. Mixing fans were used to ensure an even distribution of $\mathrm{SF}_{6}$ throughout the room, but were not used during the measurements because they are thought to initiate artificial flow paths (Liddament 1996). The $\mathrm{SF}_{6}$ was measured every 45 seconds by an Innova 1312 dual gas analyser that has a reading repeatability of 1\%. Measurements were taken from the centre of the room for periods of no less than 20 minutes and an estimation of 
the air change rate (ACR) was obtained by plotting the natural log of the tracer gas concentration against time in accordance with Liddament (1996).

\section{RESULTS}

IAQ data is presented here as a mean over the data measured for the occupied hours of 0900 to 1530 , covering working weeks in both summer and winter. The only exception to this is the winter data for School D where three working days have been used. In Figures 1 and 2, the $\mathrm{CO}_{2}$ measurements for summer and winter, respectively, are presented for nine classrooms. Here, the centre bar denotes the mean value and the upper and lower bars denote the maximum and minimum values, respectively; the dotted box denotes one standard deviation $(\sigma)$ from the mean and the horizontal dashed line denotes a relevant BB101 criterion; Figure 3 presents summer room temperatures using the same method methodology, although six additional classrooms have been added here. In Figure 4 the difference $(\Delta \mathrm{T})$ between the mean internal $\left(\mathrm{T}_{\text {in }}\right)$ and external $\left(\mathrm{T}_{\text {out }}\right)$ temperatures during the summer is presented since $\Delta \mathrm{T}$ $\leq 5^{\circ} \mathrm{C}$ represents an important $\mathrm{BB} 101$ criterion. In Figures 5 and 6 the $\mathrm{RH}$ is presented for winter and summer, respectively.

The data plotted in Figures 2-6 may readily be compared with the requirements of BB101; however, these values are closely determined by the ventilation rates in each classroom. Moreover, it is the ventilation rates, which must be achieved whatever the meteorological conditions, that are an important indicator of the performance of a split-duct ventilator and hence the success of the proposed natural ventilation strategy. Accordingly, aggregate ventilation rates are also presented here, although individual measurements with corresponding meteorological conditions are given in Jones and Kirby (2010). In Table 2, the average ventilation rates for each classroom are presented for four different natural ventilation 
strategies: (i) all windows and split-duct ventilator closed, (ii) windows closed and split-duct ventilator fully open, (iii) all windows and split-duct ventilator fully open, and (iv) windows open and split-duct ventilator closed. Here, the term "fully open" means that the ventilator's dampers are open to their full extent and that all available openable window area was employed. For the ventilation measurements, Liddament (1996) provides a thorough overview of their methodology and limitations, and the estimated errors are recorded in Table 2. There is disagreement on the accuracy of such measurements and Sherman (1990) suggests that a reasonable assumption of the overall error in this data is $\pm 10 \%$ while Persily (2006) proposes that $\pm 20 \%$ is more appropriate. Sherman also suggests that an estimate of the precision of each measurement can be made from the regression, and so the errors presented here have been calculated using the coefficient of determination $\left(\mathrm{R}^{2}\right)$, and show the extent of exponential decay and any errors from poor mixing of the tracer gas. Note also that school $\mathrm{F}$ has no manually openable windows and it was not possible to measure a ventilation rate with the windows and split-duct ventilator closed for rooms C3, C4, and D2. Finally, as BB101 quantifies ventilation rates using 1/s - person these values are presented in Figures 7 - 9, assuming a standard classroom capacity of 30 occupants in all of the classrooms except F1 and F3, which were designed for 20 occupants.

\section{DISCUSSION}

In the majority of the standards, $\mathrm{CO}_{2}$ is a key indicator of performance and in Figures 1 and 2 the measured data shows that all classrooms lie inside the BB101 maximum of $5000 \mathrm{ppm}$ for both winter and summer seasons. In the summer months, all rooms meet BB101's mean limit of $1500 \mathrm{ppm}$, although only three classrooms meet the ASHRAE (2007) maximum of 1100 ppm (assuming an external $\mathrm{CO}_{2}$ level of $400 \mathrm{ppm}$ ). However, seven classrooms do have internal $\mathrm{CO}_{2}$ concentrations of less than $1100 \mathrm{ppm}$ for approximately $84 \%$ of the time in 
summer. Furthermore, mean $\mathrm{CO}_{2}$ values also meet the requirements for category 1 of the European Standards EN15251 (2007) and so are considered to have high IAQ during the summer. The $\mathrm{CO}_{2}$ levels measured during the summer months also compare favourably with the equivalent data measured by Beisteiner and Coley (2002), who reported maximum and mean $\mathrm{CO}_{2}$ levels of $3756 \mathrm{ppm}$ and $1570 \mathrm{ppm}$, respectively, with a standard deviation of 764 ppm. The equivalent values for the current study in the summer are: $3383 \mathrm{ppm}, 687 \mathrm{ppm}$ and 246 ppm. Here, Beisteiner and Coley's NV strategy relies on opening windows, either on a single side of the building, or through cross-ventilation between two open sets of windows. In the current study it is observed that the ventilator was, on average, fully open for over $60 \%$ of the time and is never fully closed during the summer, and so an improvement in ventilation rates appears possible using either a split-duct ventilator on its own, or in conjunction with open windows.

In the winter months, Figure 2 shows that six of the nine classrooms meet BB101 requirements, whereas none meet the ASHRAE standards. In addition the classrooms are classified as having low IAQ (category 4) when compared against EN13779, and an acceptable/moderate level (category 3) when compared against the less stringent EN15251. Clearly, $\mathrm{CO}_{2}$ levels are seen to rise in all classrooms during the winter when compared to the summer months. An examination of the room temperatures in winter suggests that, on average, the split-duct ventilator is closed for $92 \%$ of the time, whilst it is highly likely that the windows have remained closed throughout the testing period. Accordingly, in winter the $\mathrm{CO}_{2}$ levels are largely controlled by background ventilation and this is the likely cause of the rise in $\mathrm{CO}_{2}$ levels seen in the winter months. In Table $3 \mathrm{CO}_{2}$ levels for winter are compared with other studies in the U.K. measured over a similar time period and here our data is generally comparable to the measurements of Mumovic et al. (2009), but lower than Coley and Beisteiner (2002). Here, it seems likely that in winter ventilation rates in each of these studies are dominated by background ventilation and so differences may simply be caused by 
differences in the fabric of each building, although it is noticeable that two of the rooms studied by Mumovic et al. (2009) adopt stack driven ventilation and here $\mathrm{CO}_{2}$ levels are similar to those found in the current study. What is clear, however, is that if one relies simply on opening windows to control $\mathrm{CO}_{2}$ levels during the winter months then there is a significant risk of failure to meet BB101 requirements. Thus, a split-duct ventilator offers an alternative strategy with the potential of lowering $\mathrm{CO}_{2}$ levels in the winter by partially opening the splitduct ventilator, although it would appear necessary to set the split-duct ventilator controls to open at a given $\mathrm{CO}_{2}$ level rather than at a pre-determined temperature, which was the strategy for the classrooms measured here. Of course, thermal comfort issues arise in the winter when ventilating using external air that is significantly colder than the internal temperature, particularly in the draught-risk zone close to the diffuser; however, a split-duct ventilator provides top-down mixing-ventilation that allows the cold external air gradually to dilute the warm internal air and so is potentially more acceptable than opening windows (Gage et al. 2001), although particular attention should be paid to the design of the diffuser to dissipate incoming flow away from the occupants.

A comparison with the data of Santamouris et al. (2008) reveals that in winter the mean $\mathrm{CO}_{2}$ concentration of $1302 \mathrm{ppm}$ measured here is lower than $62 \%$ of $\mathrm{NV}$ and $24 \%$ of MV data reported by Santamouris et al.; whereas in the summer the measured concentration of 687 ppm is lower than $97 \%$ of all NV classrooms and $84 \%$ of MV classrooms. This indicates that, when compared against the 1187 classrooms in the database of Santamouris et al., the 16 classrooms monitored in this study perform very well.

The temperature requirements of BB101 apply only to the summer time, and Figure 3 shows that all sixteen classrooms did not exceeded the maximum limit of $32^{\circ} \mathrm{C}$, nor did they exceed $28^{\circ} \mathrm{C}$ for more than 120 hours. However it should be noted that monitoring was only conducted over a representative working week and not for the whole summer season and so 
this remains only an indicator of compliance. Figure 4 shows the difference between mean internal and external temperatures, $\Delta \mathrm{T}$, which to be compliant must be less than $5^{\circ} \mathrm{C}$. The classrooms of school $\mathrm{F}$ are the only rooms not to meet this standard and this could be attributed to their comparatively large glazing area and orientation, which on the ground floor is purely south-west facing, while on the $1^{\text {st }}$ floor is split between the south-west and the north-east. These windows do have solar shields and so the high values of $\Delta \mathrm{T}$ are most likely to be due to the low mean external temperature for occupied hours of $16.8^{\circ} \mathrm{C}$, with $\sigma=3.5^{\circ} \mathrm{C}$. It should be noted, however, that during the summer months the dampers of a split-duct ventilator will automatically open to their full extent from midnight until 6 a.m. and this will provide night cooling and so help to deliver the temperatures seen in Figure 3. Thus, the ability of a split-duct ventilator to automatically deliver night cooling, without compromising security, further helps to meet IAQ requirements in classrooms.

Relative humidity levels in the summer and winter seasons are shown in Figures 5 and 6 and here mean levels are between 30-70\% for both seasons and so demonstrate compliance with U.K. building regulations (ODPM 2006). Furthermore, these limits are comparable to the findings of Mumovic et al. (2009) and Kolokotroni et al. (2002a) and so RH does not appear to be a significant cause for concern.

To achieve $\mathrm{CO}_{2}$ and temperature targets, one must provide sufficient ventilation to a room and so the measured ventilation rates presented in Table 2 provide an important indication of the performance of a split-duct ventilator. Here, the use of a split-duct ventilator on its own delivers ventilation rates that generally compare well with those reported by Mumovic et al. (2009), indicating that per capita rates of over $31 / \mathrm{s}$ - person are readily achievable (if the design occupancy levels are assumed). Table 2 also shows that, in general, the ventilation rate for a classroom increases once a split-duct ventilator is opened, although there are a few notable exceptions, such as in school G, and rather low values are also observed in classrooms 
$\mathrm{C} 1$ and $\mathrm{C} 3$. It is difficult to be certain about the reasons for this, although the rooms in school $\mathrm{G}$, and also rooms $\mathrm{C} 1$ and $\mathrm{C} 3$, all have long split-duct ventilator duct lengths. Kolokotroni et al. (2002b) noted a similar problem when studying ventilation rates from Windcatchers in a two storey office building, and so it appears there may be operational problems with long Windcatchers, although those long Windcatchers in school $\mathrm{F}$ appear to be working satisfactorily.

In Table 2, it is evident that by opening a window as well as the split-duct ventilator one can significantly increase the ventilation rates in a classroom. In general ventilation rates are seen to increase at least two-fold, although some very high multiples also appear possible. Of course, it is also interesting to isolate the effect of the split-duct ventilator by closing the dampers and opening the windows. To investigate this, ventilation rates were measured with just the windows open in classrooms C1, D1, E1, E3, and G1 (see Table 2); results show that in classrooms $\mathrm{C} 1, \mathrm{E} 1$, and E3 flow rates for windows operating on their own were between 69-76\% lower than the flow rates generated with windows and split-duct ventilator dampers open, while in D1 and G1 flow rates were 4-16\% lower. Here, the greater effective openable window area in classrooms $\mathrm{C} 1, \mathrm{E} 1$ and E3 (see Table 1) is the likely explanation for the difference in these results. Moreover, this indicates that a split-duct ventilator operating in combination with an open window will help to boost flow rates over and above that provided by windows operating autonomously, and so provide a viable method for meeting BB101 provided a sufficient number of windows are opened. These findings also agree with the measurements carried out in offices by Kirk and Kolokotroni (2004), who observed an increase in flow rates when a split-duct ventilator operates in combination with open windows. Kirk and Kolokotroni also noted that the use of windows was disliked by the occupants because they caused uncomfortable draughts, although no such observations were forthcoming in the current study. 
In order to compare measured ventilation rates with those required by BB101 it is necessary to assume the number of occupants in the classroom. Here, 30 occupants are assumed in each classroom, except in F1 and F3 where 20 are assumed. This assumption is intended to provide a worst case scenario and so may underestimate the actual volume flow rate per person if class sizes are smaller, which is possible in secondary (high) schools. Figure 7 suggests that the minimum level of $3 \mathrm{l} / \mathrm{s}$ - person cannot be achieved by background ventilation alone, except in classrooms F1 and F3 that have lower occupancy levels. When using a split-duct ventilator on its own, it is seen in Figure 8 that 3 1/s - person is met in eight classrooms and the required mean flow rate of $5 \mathrm{l} / \mathrm{s}$ - person is surpassed in a total of five classrooms. When a split-duct ventilator is combined with fully open windows then in Figure 9 it is observed that all classrooms meet $5 \mathrm{l} / \mathrm{s}$ - person apart from D2, which is very close to the required value. It is also evident that the required purge ventilation rate of $8 \pm 0.2 \mathrm{l} / \mathrm{s}$ - person is achieved in all rooms except classroom D2. Here, there is no clear explanation for the lower performance of classroom D2, as the driving forces do not differ greatly from other rooms. Thus, Figures 7-9 show that to consistently achieve the required mean and purge rates of $5 \mathrm{l} / \mathrm{s}$ - person and $8 \mathrm{l} / \mathrm{s}$ - person, respectively, it is necessary to open windows, although the exact effective opening area required in a façade to meet the guidelines is difficult to ascertain from this data. However, these results indicate that for the $\mathrm{CO}_{2}$ measurements reported in Figure 2, windows are most probably open for a significant portion of the occupied hours.

The per capita ventilation rates reported in Figures 8-9 are now compared with the data of Santamouris et al. (2008) using a mean ventilation rate for each figure. With the split-duct ventilator operating on its own, the mean ventilation rate is $3.1 \mathrm{l} / \mathrm{s}-$ person, which is greater than approximately $49 \%$ of NV and $16 \%$ of MV classrooms reported by Santamouris et al. With the split-duct ventilator and windows open, the mean ventilation rate is $13.41 / \mathrm{s}$ - person and this is greater than approximately $95 \%$ of all NV classrooms and 70\% of MV classrooms. Accordingly, the split-duct ventilator is seen to perform well relative to the extensive database 
of Santamouris et al., especially when the windows are opened. This demonstrates that combining a split-duct ventilator with open windows has the potential to provide relatively high per capita ventilation rates to school classrooms, which are greater than those specified by BB101 and ASHRAE Standard 62.1.

The findings presented here indicate that the classrooms containing a split-duct ventilator are capable of meeting BB101 criteria during the summer months, especially if they are fully integrated with openable windows. However, problems are seen to exist during the winter months. Here, ventilation rates provided by the split-duct ventilator are regulated by the dampers, which for those Windcatchers studied here are controlled according to internal temperature. Accordingly, the Windcatchers are generally inactive during the winter season and so in order to improve winter ventilation an improved control strategy it may be sensible to use $\mathrm{CO}_{2}$ as a set-point in addition to temperature to create demand-controlled ventilation. This type of strategy would incur heat losses, although for a mean flow rate of 5 1/s - person, with $\Delta \mathrm{T}=10^{\circ} \mathrm{C}$, the energy lost by ventilating a classroom would be approximately $62 \mathrm{~W}$ per person, and it is possible this could be generated by incidental heat gains from ICT equipment, or by the metabolic heat of occupants. Consideration should also be given to the provision of automatic purge ventilation during unoccupied periods to bring internal $\mathrm{CO}_{2}$ concentration back to ambient levels.

\section{CONCLUSIONS}

The IAQ and ventilation rates in 16 school classrooms in the U.K. have been measured here. Results demonstrate that a top-down natural split-duct ventilator is capable of meeting the U.K. BB101 standards. For the summer months all classrooms were able to meet the $\mathrm{CO}_{2}$ requirements and 50\% meet the minimum $3 \mathrm{l} / \mathrm{s}$ - person requirement with a ventilator 
operating autonomously. If a split-duct ventilator is operated in conjunction with open windows, then all classrooms are capable of delivering at least $31 / \mathrm{s}-$ person and $92 \%$ of classrooms meet the mean requirement of $5 \mathrm{l} / \mathrm{s}-$ person. Under this arrangement it is also noted that the purge ventilation requirement of $81 / \mathrm{s}$-person can be achieved in $92 \%$ of classrooms. Furthermore, these levels of ventilation are found to be greater than those achieved by the action of windows operating on their own. It is evident, therefore, that for those classrooms studied here a split-duct ventilator can aid in the delivery of ventilation rates that meet the UK standards during the summer months, and this also extends to meeting European and U.S. standards. However, in the winter months the split-duct ventilator is rarely opened and, although the maximum $\mathrm{CO}_{2}$ limit of $5000 \mathrm{ppm}$ is never exceeded, only $67 \%$ of classrooms meet the mean required $\mathrm{CO}_{2}$ level, and only one classroom is capable of delivering the minimum ventilation rate. This is because in winter ventilation largely relies on background levels and so it is evident that an alternative strategy is necessary, probably involving the opening of the split-duct ventilator according to $\mathrm{CO}_{2}$ levels, in order to deliver appropriate IAQ during the winter months.

The ventilation of school classrooms currently presents many problems and, when judged against relevant IAQ and ventilation standards, school classrooms are currently significantly under-ventilated. A top-down natural split-duct ventilator has been shown here to offer the potential to significantly improve natural ventilation rates in classrooms and to aid in the compliance with IAQ standards for schools.

\section{ACKNOWLEDGEMENTS}

This research was carried out with financial support from the Engineering and Physical Sciences Research Council (EPSRC) and Monodraught Ltd. 


\section{REFERENCES}

ASHRAE (2007) Ventilation for Acceptable Indoor Air Quality, Atlanta, GA, American Society of Heating, Refrigeration, and Air-Conditioning Engineers, (ASHRAE Standard 62.1)

Bakó-Biró, Z., Wargocki, P., Weschler, C.J. and Fanger, P.O. (2004) Effects of pollution from personal computers on perceived air quality, SBS symptoms and productivity in offices, Indoor Air, 14, 178-187.

Bakó-Biró, Z., Clements-Croome, D.J., Kochhar, N., Awbi, H.B. and Williams, M.J. (2012) Ventilation rates in schools and pupils' performance. Building and Environment 48(0), 215223.

Beisteiner, A. and Coley, D.A. (2002) Carbon Dioxide Levels and Summertime Ventilation Rates in UK Schools, International Journal of Ventilation, 1, 181-187.

Chaloulakou, A. and Mavroidis, I. (2002) Comparison of indoor and outdoor concentrations of $\mathrm{CO}$ at a public school. Evaluation of an indoor air quality model. Atmospheric Environment, 36, 1769-1781.

Conceição, E.Z.E. and Lúcio, M.M.J.R. (2006) Air Quality Inside a School Building: Air Exchange Monitoring, Evolution of Carbon Dioxide and Assessment of Ventilation Strategies, International Journal of Ventilation, 5, 259-270.

Coley, D.A., Greeves, R. and Saxby, B.K. (2007) The Effect of Low Ventilation Rates on the Cognitive Function of a Primary School Class. International Journal of Ventilation, 6(2), 107-112.

Coley, D.A. and Beisteiner, A. (2002) Carbon Dioxide Levels and Ventilation Rates in Schools, International Journal of Ventilation, 1, 45-52. 
Daisey, J.M., Angell, W.J. and Apte, M.G. (2003) Indoor air quality, ventilation and health symptoms in schools: an analysis of existing information, Indoor Air, 13, 53-64.

DfES (2002) Building Bulletin 95 - Schools for the Future, Department for Education and Skills, London, U.K.

DfES (2006) Building Bulletin 101 - Ventilation of School Buildings. Department for Education and Skills, London, U.K.

Elmualim, A.A. and Awbi, H.B. (2002) Wind Tunnel and CFD Investigation of the Performance of Windcatcher Ventilation Systems. International Journal of Ventilation, 1(1), 53-64.

Elmualim, A.A. (2006) Dynamic Modelling of a Wind Catcher/Tower Turret for Natural Ventilation, Building Services Engineering Research and Technology, 27, 165-182.

EN13779 (2004) Ventilation for Non-Residential Buildings - Performance requirements for Ventilation and Room-Conditioning System, British Standards Institute, London, U.K.

EN15251 (2007) Indoor Environment Input Parameters for Design and Assessment of Energy Performance of Buildings Addressing Indoor Air Quality, Thermal Environment, Lighting and Acoustics, British Standards Institute, London, U.K.

Gage, S.A., Hunt, G.R. and Linden, P.F. (2001) Top Down Ventilation and Cooling, Journal of Architecture and Planning Research, 18, 286-301.

Geelen, L.M.J., Huijbregts, M.A.J., Ragas, A.M.J., Bretveld, R.W., Jans, H.W.A., Van Doorn, W.J., Evertz, S.J.C.J. and Van der Zijden, A. (2008) Comparing the effectiveness of interventions to improve ventilation behavior in primary schools, Indoor Air, 18, 416-424.

Godwin, C. and Batterman, S. (2007) Indoor air quality in Michigan schools, Indoor Air, 17, 109-121. 
Grimsrud, D., Bridges, B. and Schulte, R. (2006) Continuous measurements of air quality parameters in schools, Building Research \& Information, 34, 447 - 458.

Hellwig, R.T., Antretter, F., Holm, A. and Sedlbauer, K. (2009), Investigations into Indoor Environment Conditions and Natural Ventilation in School Buildings, Bauphysik, 31, 89-98.

Jones, B.M. and Kirby, R. (2010). The Performance of Natural Ventilation Windcatchers in Schools - A Comparison between Prediction and Measurement. International Journal of Ventilation 9(3), 273-286.

Jones, B.M. and Kirby, R. (2009) Quantifying the Performance of a Top-Down Natural Ventilation Windcatcher ${ }^{\mathrm{TM}}$, Building and Environment, 44, 1925-1934.

Kirk, S. and Kolokotroni, M. (2004) Windcatchers in Modern UK Buildings: Experimental Study, International Journal of Ventilation, 3, 67-78.

Kolokotroni, M., Ge, Y.T. and Katsoulas, D. (2002a) Monitoring and Modelling Indoor Air Quality and Ventilation in Classrooms within a Purpose-Designed Naturally Ventilated School, Indoor and Built Environment, 11, 316-326.

Kolokotroni, M., Ayiomamitis, A. and Ge, Y.T. (2002b) The Suitability of Wind Driven Natural Ventilation Towers for Modern Offices in the UK: A Case Study, World Renewable Energy Congress, Cologne, Germany.

Laxen, D.P.H. and Noordally, E. (1987) Nitrogen Dioxide Distribution in Street Canyons, Atmospheric Environment, 21, 1899-1903.

Liddament, M.W. (1996) AIVC: A Guide to Energy Efficient Ventilation, Oscar Faber.

Mendell, M.J. and Heath, G.A. (2005) Do Indoor Pollutants and Thermal Conditions in Schools Influence Student Performance? A Critical Review of the Literature, Indoor Air, 15, $27-52$. 
Mumovic, D., Palmer, J., Davies, M., Orme, M., Ridley, I., Oreszczyn, T., Judd, C., Critchlow, R., Medina, H.A., Pilmoor, G., Pearson, C. and Way, P. (2009) Winter Indoor Air Quality, Thermal Comfort and Acoustic Performance of Newly Built Secondary Schools in England, Building and Environment, 44, 1466-1477.

Myhrvold, A.N., Olsen, E., and Lauridsen, O. (1996) Indoor Environment in Schools - Pupils Health and Performance in Regard to $\mathrm{CO}_{2}$ Concentrations, Indoor Air '96: The 7th International Conference on Indoor Air Quality and Climate, Nagoya, Japan.

ODPM (2006) Building Regulations 2000, Part F (Ventilation), Office of the Deputy Prime Minister, London, U.K.

Persily, A.K. (1997) Evaluating Building IAQ and Ventilation with Indoor Carbon Dioxide, ASHRAE Transactions, 103, 193-204.

Persily, A.K. (2006) What We Think We Know About Ventilation, International Journal of Ventilation, 5, 275-290.

Prill, R., D. Blake, et al. (2002). School Indoor Air Quality Assessment and Program Implementation. Indoor Air 2002, Moneterey, California.

Santamouris, M., Synnefa, A., Asssimakopoulos, M., Livada, I., Pavlou, K., Papaglastra, M., Gaitani, N., Kolokotsa, D. and Assimakopoulos, V. (2008) Experimental investigation of the air flow and indoor carbon dioxide concentration in classrooms with intermittent natural ventilation, Energy and Buildings, 40, 1833-1843.

Seppänen, O.A., Fisk, W.J. and Mendell, M.J. (1999) Association of Ventilation Rates and $\mathrm{CO} 2$ Concentrations with Health and Other Responses in Commercial and Institutional Buildings, Indoor Air, 9, 226-252. 
Shaughnessy, R.J., Haverinen-Shaughnessy, U., Nevalainen, A. and Moschandreas, D. (2006) A preliminary study on the association between ventilation rates in classrooms and student performance, Indoor Air, 16, 465-468.

Shendell, D.G., Prill, R., Fisk, W.J., Apte, M.G., Blake, D. and Faulkner, D. (2004) Associations between classroom $\mathrm{CO} 2$ concentrations and student attendance in Washington and Idaho, Indoor Air, 14, 333-341.

Sherman M.H. (1990). Tracer-gas techniques for measuring ventilation in a single zone. Building and Environment 25, 365-374.

Smedje, G. and Norback, D. (2000) New Ventilation Systems at Select Schools in Sweden Effects on Asthma and Exposure, Archives of Environmental Health, 55, 18-25.

Smedje, G., Norback, D. and Edling, C. (1997) Subjective Indoor Air Quality in Schools in Relation to Exposure, Indoor Air, 7, 143-150.

Stranger, M., Potgieter-Vermaak, S.S. and Van Grieken, R. (2008) Characterization of indoor air quality in primary schools in Antwerp, Belgium, Indoor Air, 18, 454-463.

Van Dijken, F., Van Bronswijk, J.E.M.H. and Sundell, J. (2006) Indoor environment and pupils' health in primary schools, Building Research \& Information, 34, 437-446.

Wargocki, P., Sundell, J., Bischof, W., Brundrett, G., Fanger, P.O., Gyntelberg, F., Hanssen, S.O., Harrison, P., Pickering, A., Seppänen, O. and Wouters, P. (2002) Ventilation and health in non-industrial indoor environments: report from a European Multidisciplinary Scientific Consensus Meeting (EUROVEN), Indoor Air, 12, 113-128.

Wargocki, P. and Wyon, D.P. (2007a) The Effects of Moderately Raised Classroom Temperatures and Classroom Ventilation Rate on the Performance of Schoolwork by Children, HVAC\&R Research, 13, 193-220. 
Wargocki, P. and Wyon, D.P. (2007b) The Effects of Outdoor Air Supply Rate and Supply Air Filter Condition in Classrooms on the Performance of Schoolwork by Children, $H V A C \& R$ Research, 13, 165-191. 


\section{FIGURE CAPTIONS}

Figure 1. Measured $\mathrm{CO}_{2}$ levels for occupied hours in summer.

Figure 2. Measured $\mathrm{CO}_{2}$ levels for occupied hours in winter.

Figure 3. Measured temperature for occupied hours in summer.

Figure 4. Difference between mean internal and external temperatures $(\Delta \mathrm{T})$ for occupied hours in summer.

Figure 5. Measured RH for occupied hours in summer.

Figure 6. Measured RH for occupied hours in winter.

Figure 7. Estimated ventilation rate per person: Windcatcher closed and windows closed.

Figure 8. Estimated ventilation rate per person: Windcatcher open and windows closed.

Figure 9. Estimated ventilation rate per person: Windcatcher open and windows open. 
Table 1.

Classroom parameters

\begin{tabular}{|c|c|c|c|c|c|c|c|c|}
\hline Room & Floor & $\begin{array}{c}\text { Volume } \\
\left(\mathrm{m}^{3}\right)\end{array}$ & $\begin{array}{l}\text { Windcatcher } \\
\text { CSA }\left(\mathrm{m}^{2}\right)\end{array}$ & $\begin{array}{l}\text { Duct length } \\
\text { (m) }\end{array}$ & $\begin{array}{c}\text { Total glazing } \\
\text { area }\left(\mathrm{m}^{2}\right)\end{array}$ & $\begin{array}{c}\text { Glazing } \\
\text { Orientation }\end{array}$ & $\begin{array}{l}\text { Openable } \\
\text { Windows }\end{array}$ & $\begin{array}{c}\text { Openable window } \\
\text { area }\left(\mathrm{m}^{2}\right)\end{array}$ \\
\hline$\overline{\mathrm{C} 1}$ & Ground & 148 & 0.77 & 4.8 & 3.15 & South & 6×Top Hung & 0.87 \\
\hline $\mathrm{C} 2$ & $1 \mathrm{st}$ & 172 & 0.77 & 1.0 & 3.15 & South & $6 \times$ Top Hung & 0.87 \\
\hline $\mathrm{C} 3$ & Ground & 148 & 0.77 & 4.8 & 3.15 & South & 6×Top Hung & 0.87 \\
\hline $\mathrm{C} 4$ & $1 \mathrm{st}$ & 172 & 0.77 & 1.0 & 3.15 & South & $6 \times$ Top Hung & 0.87 \\
\hline D1 & Ground & 272 & 0.64 & 1.0 & 6.53 & North & $5 \times$ Top Hung & 1.53 \\
\hline D2 & Ground & 272 & 0.64 & 1.0 & 6.53 & North & $5 \times$ Top Hung & 1.53 \\
\hline D3 & Ground & 272 & 0.64 & 1.0 & 6.53 & North & 5×Top Hung & 1.53 \\
\hline E1 & Ground & 157 & 0.46 & 4.6 & 7.87 & South East & $4 \times$ Bottom Hung & 0.49 \\
\hline E3 & Ground & 157 & 0.46 & 4.6 & 7.87 & South East & $4 \times$ Bottom Hung & 0.49 \\
\hline $\mathrm{F} 1$ & Ground & 323 & 0.92 & 7.0 & 12.10 & South West & None & $\mathrm{n} / \mathrm{a}$ \\
\hline $\mathrm{F} 2$ & $1 \mathrm{st}$ & 549 & 0.58 & 1.0 & 12.34 & $\begin{array}{c}\text { South West and } \\
\text { North East } \\
\text { clerestory }\end{array}$ & None & $\mathrm{n} / \mathrm{a}$ \\
\hline F3 & Ground & 323 & 0.92 & 7.0 & 12.10 & South West & None & $\mathrm{n} / \mathrm{a}$ \\
\hline F4 & $1 \mathrm{st}$ & 498 & 0.58 & 1.0 & 12.34 & $\begin{array}{c}\text { South West and } \\
\text { North East } \\
\text { clerestory }\end{array}$ & None & $\mathrm{n} / \mathrm{a}$ \\
\hline G1 & Ground & 203 & 0.64 & 5.5 & 4.61 & West & $4 \times$ Sash & 1.84 \\
\hline $\mathrm{G} 2$ & Ground & 185 & 0.64 & 5.8 & 4.61 & West & $2 \times$ Sash & 1.84 \\
\hline G3 & Ground & 203 & 0.64 & 5.5 & 9.69 & West and South & $2 \times$ Sash & 3.88 \\
\hline
\end{tabular}


Table 2.

Volume flow rate (litres per second) measured for each classroom

\begin{tabular}{ccccc}
\hline $\begin{array}{l}\text { Windcatcher } \\
\text { Dampers }\end{array}$ & Closed & Open & Open & Closed \\
\hline $\begin{array}{c}\text { Window } \\
\text { Position }\end{array}$ & Closed & Closed & Open & Open \\
\hline Room & & & \\
\hline C1 & $4.1 \pm 0.2$ & $30.8 \pm 1.5$ & $238.7 \pm 3.8$ & \\
C2 & $4.1 \pm 0.6$ & $168.1 \pm 3.1$ & $247.8 \pm 2.5$ & $59.6 \pm 4.2$ \\
C3 & & $32.6 \pm 2.6$ & $393.9 \pm 4.6$ & \\
C4 & & $121.6 \pm 2.8$ & $320.3 \pm 3.0$ & \\
D1 & $25.7 \pm 2.4$ & $54.5 \pm 45.8$ & $234.5 \pm 51.6$ & $225.5 \pm 31.6$ \\
D2 & & $168.7 \pm 18.6$ & $133.9 \pm 68.3$ & \\
D3 & & $92.3 \pm 38.8$ & $254.2 \pm 30.5$ & \\
E1 & $1.7 \pm 1.3$ & $24.5 \pm 2.8$ & $395.4 \pm 4.2$ & $95.2 \pm 1.9$ \\
E3 & $10.0 \pm 1.8$ & $19.2 \pm 2.1$ & $352.6 \pm 12.5$ & $111.0 \pm 1.2$ \\
F1 & $72.7 \pm 8.0$ & $183.7 \pm 6.9$ & $\mathrm{n} / \mathrm{a}$ & $\mathrm{n} / \mathrm{a}$ \\
F2 & $62.5 \pm 15.0$ & $109.5 \pm 8.1$ & $\mathrm{n} / \mathrm{a}$ & $\mathrm{n} / \mathrm{a}$ \\
F3 & $73.6 \pm 2.9$ & $119.5 \pm 7.2$ & $\mathrm{n} / \mathrm{a}$ & $\mathrm{n} / \mathrm{a}$ \\
F4 & $30.4 \pm 1.5$ & $179.8 \pm 9.0$ & $\mathrm{n} / \mathrm{a}$ & $\mathrm{n} / \mathrm{a}$ \\
G1 & $17.5 \pm 7.5$ & $16.4 \pm 10.0$ & $1245.6 \pm 62.3$ & $1037.1 \pm 62.2$ \\
G2 & Negligible & $11.3 \pm 3.2$ & $432.9 \pm 13.0$ & \\
G3 & $14.1 \pm 2.4$ & $16.4 \pm 11.5$ & $555.9 \pm 11.1$ & \\
\hline & & & & \\
\hline
\end{tabular}


Table 3.

$\mathrm{CO}_{2}$ concentration in $\mathrm{UK}$ school classrooms in winter with ventilation type

\begin{tabular}{|c|c|c|c|c|}
\hline $\begin{array}{l}\mathrm{CO}_{2} \\
(\mathrm{ppm})\end{array}$ & $\begin{array}{c}\text { Jones \& Kirby } \\
\text { NV }\end{array}$ & $\begin{array}{c}\text { Mumovic et al (2008) } \\
\text { NV }\end{array}$ & $\begin{array}{c}\text { Mumovic et al (2008) } \\
\text { MV/MM }\end{array}$ & $\begin{array}{c}\text { Coley \& Beisteiner (2002) } \\
\text { NV }\end{array}$ \\
\hline Mean & 1302 & 1459 & 869 & 1957 \\
\hline$\sigma$ & 444 & 560 & 225 & 917 \\
\hline Max & 4336 & 2917 & 1254 & 4108 \\
\hline
\end{tabular}

NV, Natural ventilation; MV, Mechanical ventilation; MM, Mixed-mode ventilation 


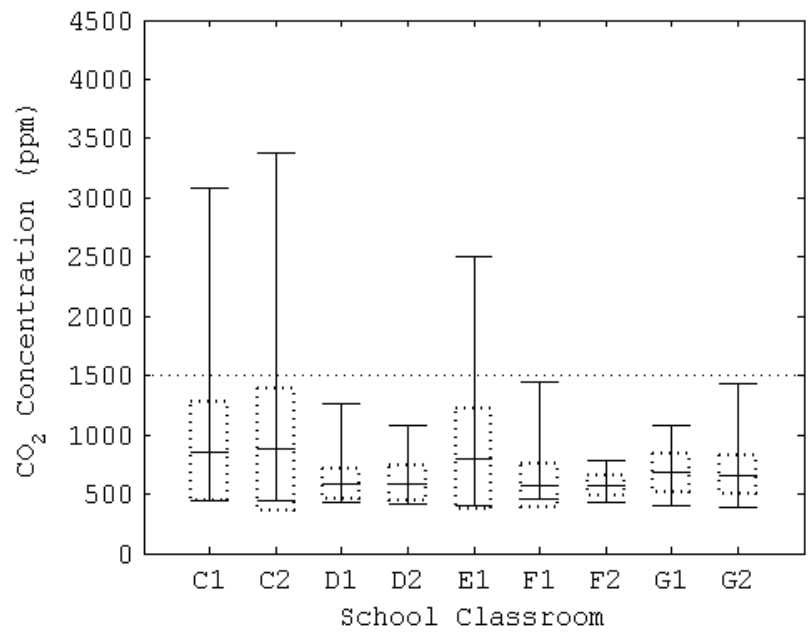

Figure 1. 


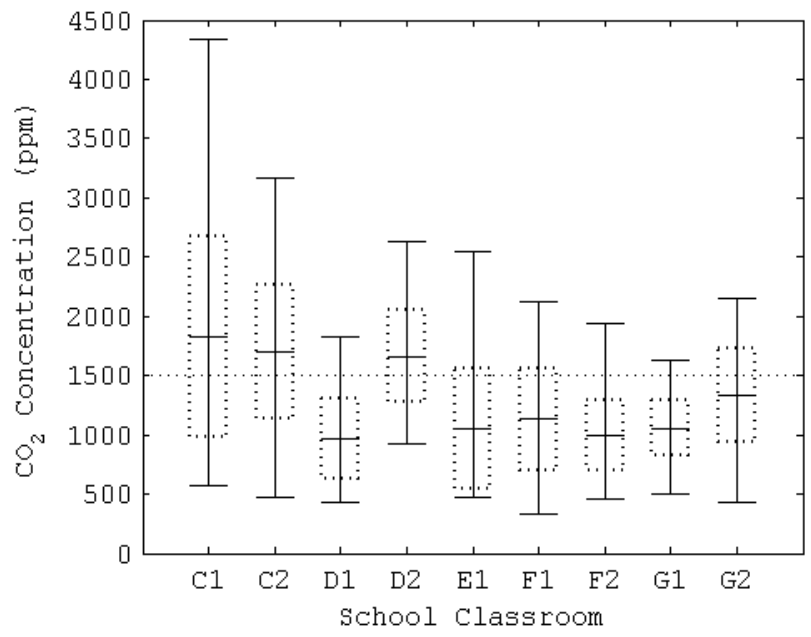

Figure 2. 


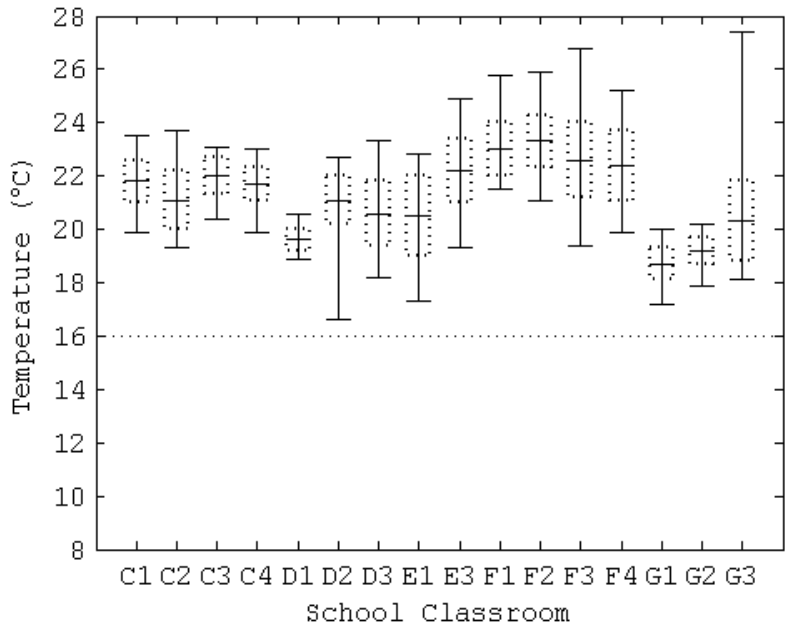

Figure 3. 


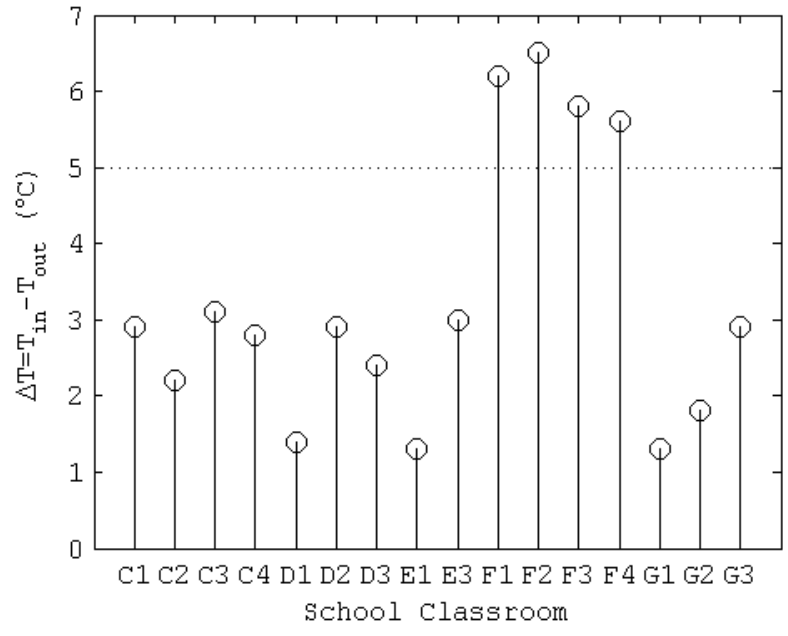

Figure 4 . 


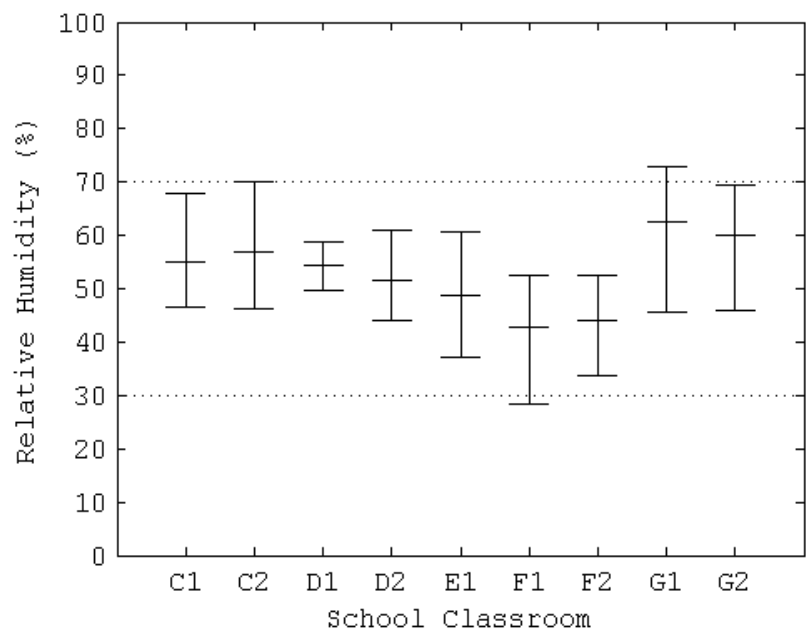

Figure 5. 


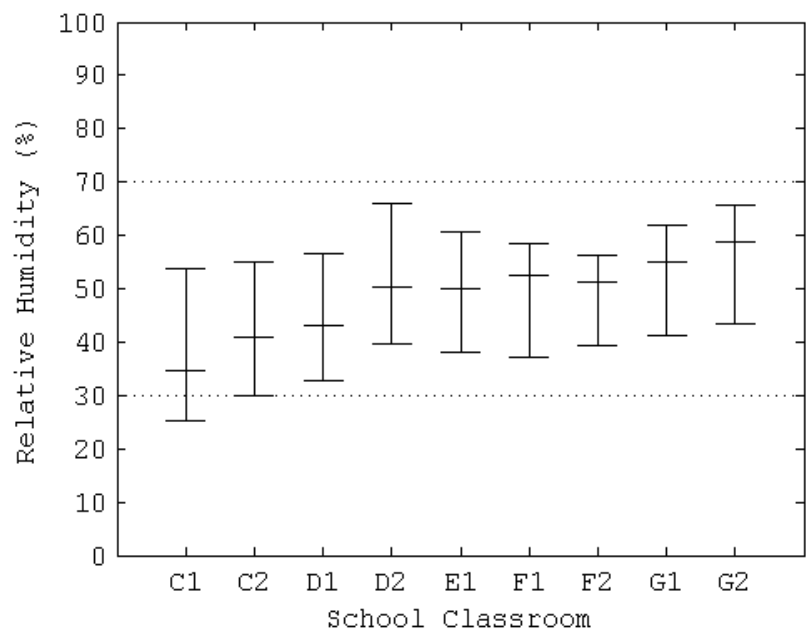

Figure 6. 


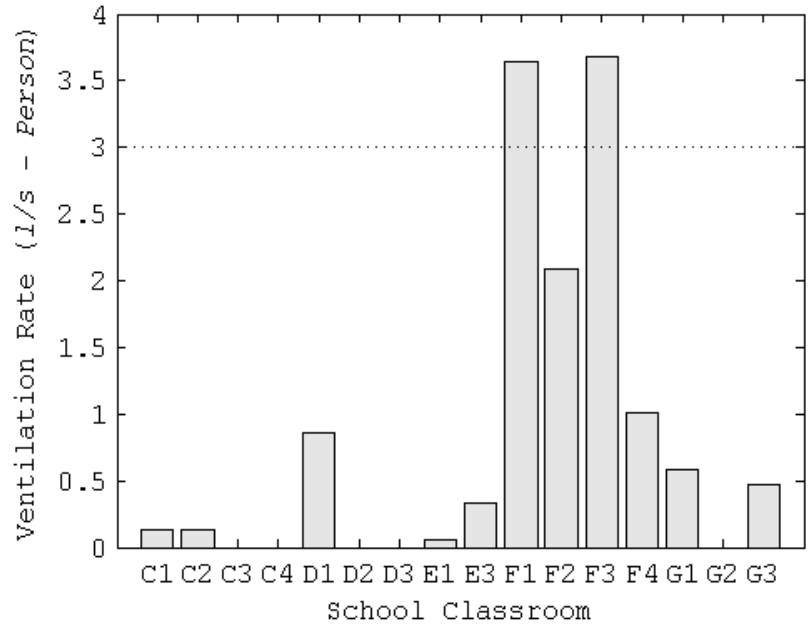

Figure 7. 


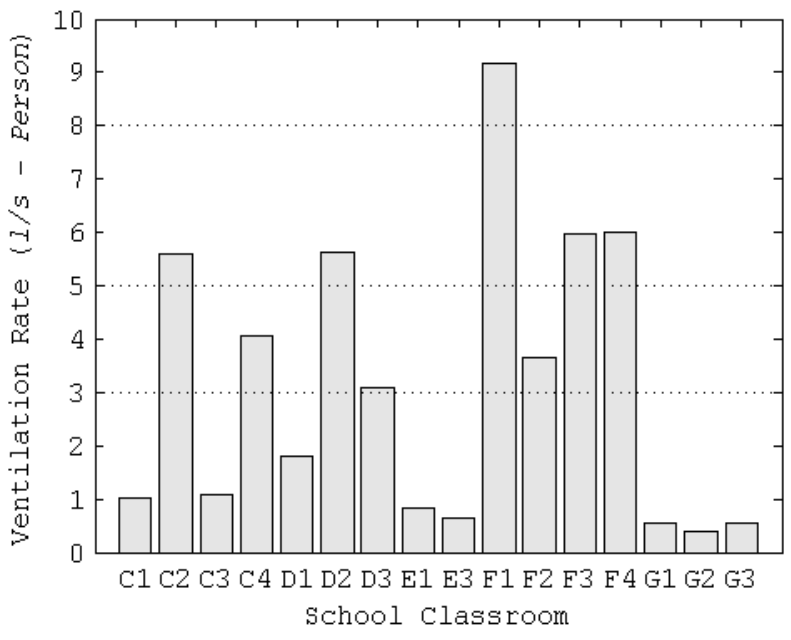

Figure 8 . 


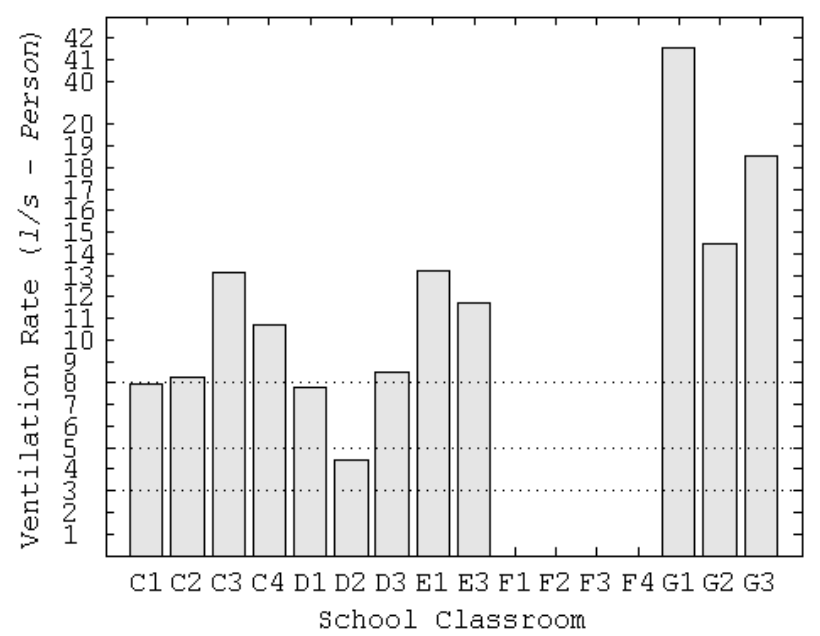

Figure 9. 